\title{
PERAN KH. ABDULLAH ABBAS DALAM PERKEMBANGAN PONDOK BUNTET PESANTREN SERTA PENGARUHNYA SEBAGAI KIAI KHOS DI INDONESIA
}

\author{
Jihan Amalia Hasanah \\ IAIN Syekh Nurjati Cirebon (jihand33@gmail.com)
}

\begin{abstract}
KH. Abdullah Abbas is a khoss kiai who became the reference of Muslims in Indonesia. It also has many services. In addition to being the Chief of Staff of the Hezbollah Battalion during the colonial period, he was active in NU activities and struggles. This research becomes more interesting, because KH. Abdullah Abbas has also made Pondok Buntet Pesantren growing and increasingly known by the masyakarat Indonesia. In addition to his khos-an, also because KH. Abdullah Abbas seeks to improve the quality and quantity of education by combining the salaf system and the kholaf system in Buntet Pesantren. On that basis, researchers are interested to reveal more deeply related to the role of $\mathrm{KH}$. Abdullah Abbas in developing Pondok Buntet Pesantren and its influence as kiai khos in Indonesia.
\end{abstract}

Keywords: Pesantren, Buntet, KH. Abdullah Abbas, Kiai khos, Hezbollah

\begin{abstract}
Abstrak
KH. Abdullah Abbas adalah seorang kiai khos yang menjadi rujukan umat Islam di Indonesia. Ia juga mempunyai banyak jasa. Selain pernah menjadi Kepala Staf Batalyon Hizbullah pada masa penjajahan, ia pun aktif dalam kegiatan dan perjuangan NU. Penelitian ini menjadi lebih menarik, karena KH. Abdullah Abbas juga telah menjadikan Pondok Buntet Pesantren semakin berkembang dan semakin dikenal oleh masyakarat Indonesia. Selain karena ke-khos-annya,juga karena KH. Abdullah Abbas berupaya meningkatkan kualitas dan kuantitas pendidikan dengan memadukan antara sistem salaf dan sistem kholaf di Buntet Pesantren. Atas dasar itulah, peneliti tertarik untuk menguak lebih dalam terkait dengan peranan $\mathrm{KH}$. Abdullah Abbas dalam mengembangkan Pondok Buntet Pesantren serta pengaruhnya sebagai kiai khos di Indonesia.
\end{abstract}

Kata Kunci: Pesantren, Buntet, KH. Abdullah Abbas, Kiai khos, Hizbullah

\section{A. Pendahuluan}

Pesantren merupakan lembaga pendidikan Islam tradisional yang tumbuh dan berkembang di tengahtengah masyarakat muslim dan ikut terlibat langsung dalam upaya mencerdaskan kehidupan bangsa dan telah memberikan kontribusi yang cukup signifikan dalam penyelenggaraan pendidikan di Indonesia. Menurut Nurcholis
Madjid, secara historis pesantren tidak hanya identik dengan makna keislaman akan tetapi juga mengandung makna keaslian (indigenous) Indonesia. Dalam prespektif historis, lahirnya pesantren bukan sekedar untuk memenuhi kebutuhan akan pentingnya pendidikan, tetapi juga untuk penyiaran agama Islam. 
Pesantren bukan hanya mampu bertahan, tetapi lebih dari pada itu, dengan penyesuaian, akomodasi, dan konsesi yang diberikannya, pesantren mampu mengembangkan diri, dan bahkan kembali menempatkan diri pada posisi yang penting dalam sistem pendidikan nasional Indonesia secara keseluruhan.

Pondok, masjid, santri, pengajaran kitab Islam klasik dan Kiai adalah lima elemen dasar tradisi pesantren. Namun menurut Hamdan Farchan Syarifuddin, Pesantren sebagai institusi sosial tidak hanya berbentuk lembaga dengan seperangkat elemen pendukungnya seperti masjid, ruang mengaji, asrama santri dan beberapa guru dan kiai, tetapi pesantren merupakan entitas budaya yang mempunyai implikasi terhadap kehidupan sosial yang melingkupinya.

Inilah yang akan menjadi kajian penelitian ini dengan menampilkan profil sebuah Pondok Pesantren tradisional yang cukup tua di Nusantara ini, yaitu Pondok Buntet Pesantren Cirebon. Buntet Pesantren adalah nama sebuah pondok pesantren yang umurnya cukup tua. Berdiri sejak abad ke 18 tepatnya tahun 1750 . Tokoh Utama yang pertama kali mendirikan pesantren ini adalah seorang Mufti Besar Kesultanan Cirebon bernama Mbah Muqoyyim. Latar belakangnya adalah karena ia memiliki sikap non kooperatif terhadap penjajah Belanda waktu itu, sehingga lebih kerasan (betah) tinggal dan mengajar di tengah masyarakat ketimbang di Istana Kesultanan Cirebon. Dikutip dari buku Intelektualisme Pesantren, alasan Mbah Muqoyyim memilih tempat di Buntet, karena tempat ini pernah digunakan oleh Mbah Kuwu Cirebon membuka padepokan.

Setelah merasa cocok bertempat tinggal di perkampungan dan memberikan dakwah keagamaan, akhirnya ia mendirikan sebuah pondok pesantren yang cukup terekenal bernama Pondok Buntet Pesantren. Pondok Buntet Pesantren dikenal tidak hanya dari segi mutu pendidikan yang disajikan, sebagai pesantren salaf yang mengajarkan berbagai kitab kuning bertaraf babon, tetapi pesantren ini juga memiliki peran-peran sosial politik yang diambil oleh para pemimpinnya. Kualitas pengajian dan kharisma seorang kiai merupakan daya tarik utama dalam sistem pendidikan pesantren salaf. Namun seiring dengan perkembangan zaman, Pondok Buntet Pesantren berupaya meningkatkan kualitas dan kuantitas pendidikan dengan memadukan antara Sistem Salaf dan Sistem Kholaf. 
Kepemimpinan Pondok Buntet Pesantren dipimpin oleh seorang Kiai yang seolah-olah membawahi kiai-kiai lainnya yang memimpin masing-masing asrama (pondokan). Segala urusan ke luar diserahkan kepada sesepuh ini. Lebih jelasnya periodisasi kepemimpinan Kiai Sepuh ini berturut-turut hingga masa-masa dipimin oleh Kiai yang dikenal Khos yaitu KH. Abdullah Abbas (Perode tahun 1989 - 2007). Pada masa kepemimpinannya, antara lain berhasil mengoptimalkan upaya meningkatkan kualitas dan kuantitas pendidikan dengan memadukan antara sistem salaf dan sistem kholaf. Pada 1992, Pesantren Buntet bukan lagi sebagai pesantren salaf tetapi telah menjadi Pesantren Terpadu antara pesantren salaf dan pesantren modern.

KH.Abdullah Abbas termasuk Kiai Khos yang menjadi rujukan umat Islam Indonesia. Semasa hidupnya ia banyak menerima tamu dari berbagai lapisan masyarakat, mulai dari kalangan wong cilik sampai kalangan pejabat Pemerintah Indonesia.

Sosok KH. Abdullah Abbas karena mempunyai segudang prestasi namun tak banyak yang mengetahui. Pada masanya, banyak pencapaian yang berhasil ia sumbangkan demi perkembangan Pondok Buntet Pesantren. Sebagai salah satu Kiai
Khos yang menjadi rujukan dan panutan di Indonesia, telah banyak sekali yang sudah berkunjung ke Buntet Pesantren untuk menemuinya. Mulai dari kalangan wali santri, pejabat daerah, anggota DPR, menteri sampai presiden. Penulis juga akan mencoba membuktikan kebenaran dari apa yang senantiasa di sampaikan $\mathrm{KH}$. Kholil Bisri ataupun adiknya $\mathrm{KH}$. Mustofa Bisri pada awal tahun 2000an, bahwa paku bumi tanah Jawa adalah Triple A; Abdullah Faqih di Jawa Timur, Abdullah Salam di Jawa Tengah dan Abdullah Abbas di Jawa Barat. Maka tak berlebihan jika sudah banyak yang mengakui bahwa KH. Abdullah Abbas merupakan salah satu tokoh sentral di Indonesia.

Tulisan ini didasarkan penelitian, yang memakai metodologi sejarah yang terdiri dari langkah-langkah tertentu, yaitu: 1) Heuristik, 2) Verifikasi atau Kritik, 3) Interpretasi, dan 4) Historiografi.

\section{B. Peran KH. Abdullah Abbas dalam Perkembangan Pondok Buntet Pesantren}

KH. Abdullah Abbas dikenal sebagai salah satu figur yang berasal dari pesantren yang cukup banyak memberikan kontribusi positif dalam rangka membangun tatanan masyarakat yang beradab, berkeadilan sosial, dan religius. $\mathrm{KH}$. 
Abdullah Abbas berupaya untuk memperbaiki kekurangankekurangan yang ada pada sekaligus memenuhi tuntutan masyarakat yang menginginkan agar pondok pesantren tidak hanya membuka lembaga pendidikan yang mengajarkan materi pengetahuan agama, tapi juga lembaga-lembaga pendidikan yang mengajarkan pengetahuan agama, pengetahuan umum dan keterampilan.

Motivasi para kiai Buntet semakin kuat untuk menjadikan Pondok Pesantren Buntet bukan hanya sebagai sebuah sistem lembaga kependidikan, tapi lebih dari itu yaitu jadi pelopor dalam pengembangan ilmu pengetahuan dan teknologi (Iptek). Motivasi ini diimplementasikan ketika KH. Abdullah Abbas yang memimpin Pesantren Buntet.

Pada kepemimpinan $\mathrm{KH}$. Abdullah Abbas, telah ditempuh beberapa kebijakan. Pertama, tidak lagi menerapkan sistem single management. Ini ditandai dengan telah dibentuk Yayasan Pendidikan Islam (YPI) pada 1992. Kedua, Pesantren Buntet bukan lagi sebagai Pesantren Salaf tetapi telah menjadi Pesantren Terpadu antara pesantren salaf dan pesantren modern) yaitu dengan telah dibukanya lembagalembaga pendidikan keterampilan seperti pada tahun ajaran 1995/1996
Pesantren Buntet mendirikan Madrasah Aliyah Khusus (MAK) yang dalam proses belajarmengajarnya lebih menekankan kepada keterampilan berbahasa asing, Tahun ajaran 1998/1999, MAK NU dipimpin oleh Drs. KH. Yusuf Ma'mun, memiliki murid berjumlah 74 orang. MAK NU memiliki tenaga pengajar sebanyak 16 orang, terdiri dari para sarjana S1 dari IAIN Cirebon, UIN Jakarta, UIN Yogyakarta, Universitas Darul Ulum Makkah dan Universitas alAzhar Mesir yang memiliki kemampuan berbahasa asing dan dibantu oleh para pengelola lembaga bahasa asing (LBA) dan pada tahun akademik 1996/1997 telah didirikan lembaga pendidikan tinggi AKPER yang dalam kurikulumnya lebih menekankan kepada keterampilan perawat kesehatan.

1. KH. Abdullah Abbas Mendirikan AKPER

Keinginan Kiai Abdullah itu berawal dari ketika ia menjalani rawat inap di rumah sakit. Ia memperhatikan seorang perawat berjilbab yang pada saat itu sangat jarang ada perawat yang memakai hijab, yang sedang memeriksa kesehatan KH. Abdullah Abbas. Setiap kali melakukan sesuatu, perawat tersebut mengucapkan basmalah. 
Berawal dari situ kemudian Kiai Abdullah Abbas mengutarakan keinginannya untuk membuat sekolah kesehatan berbasis pesantren kepada anaknya. Ia beranggapan bahwa ketika para perawat itu didik dan diajarkan di lingkungan pondok pesantren maka dengan sendirinya akhlak dan perilakunya juga menjadi baik.

Keinginan KH. Abdullah Abbas amat sangat sulit direalisasikan. Hal ini dikarenakan Sekolah Kesehatan (AKPER) sangat tinggi biaya pembangunan di tengah lingkungan Pondok Buntet Pesantren yang masih menggunakan sistem pengajaran ilmu pengetahuan salaf. Namun dengan penuh semangat KH. Abdullah Abbas terus berupaya mewujudkan keinginannya tersebut sampai pada waktu acara Haul Sesepuh Pondok Buntet Pesantren tahun 1994, ia dipertemukan dengan Kepala Menteri Pertahanan dan Keamanan, Edi Sudrajat. Melihat peran KH. Abdullah Abbas yang sangat banyak terutama dalam kemerdekaan Indonesia, Menhankam mengabulkan impian $\mathrm{KH}$.
Abdullah Abbas yaitu mendirikan Akademi Perawatan. Pada saat itu AKPER Buntet Pesantren merupakan sekolah keperawatan pertama di lingkungan pondok pesantren sewilayah Jawa Barat.

Untuk meningkatan kualitas AKPER, KH. Abdullah Abbas dan kiai Buntet yang lain, dengan keteguhan dan keyakinannya, terus berusaha dan akhirnya pembangunan berjalan dengan lancar dibantu oleh KH. Fahim Chowi dan KH. Abdul Aziz Achyadi. Mereka bekerja sama dengan berbagai pihak dalam pengadaan tenaga pengajar yang profesional dan penggalangan dana. Dalam pengadaan dosen dan tenaga administrasi yang profesional, AKPER melakukan kerja sama dengan

AKPER

Muhammadiyah Cirebon, Akademi Bidan (AKBID) Cirebon, RSUD Gunung Djati, RS Pelabuhan Cirebon dan RS Ciremai Cirebon. Sampai pada akhirnya AKPER dibuka pada tahun $1997 .{ }^{1}$ 
Pada tahun akademik 1998/1999, direktur AKPER adalah Kolonel Drs. KH. Abdul Aziz Achyadi dengan mahasiswa berjumlah 80 orang terdiri dari 17 orang mahasiswa dan 63 orang mahasiswi. Dosen profesional yang ada hingga tahun akademik ke dua berjumlah 20 orang dosen.

Pemikiran KH. Abdullah Abbas terhadap bentuk atau jenis pendidikan terfokus kepada upaya bagaimana agar lembaga pendidikan yang ada di Pesantren Buntet dapat mengikuti perkembangan zaman dan sesuai dengan tuntutan masyarakat sebagai pengguna. Karena itu, usaha apapun demi kemajuan LPI dan YPI akan diperjuangkan dengan cara menyatukannya menjadi YLPI.

2. KH. Abdullah Abbas membentuk YLPI

Pada awalnya Pondok pesantren Buntet, terdapat dua kelembagaan yang mengkoordinasikan lembagalembaga pendidikan yaitu LPI (Lembaga Pendidikan Islam) dan YPI (Yayasan Pendidikan Islam). Kenyataan ini sering membuat

masyarakat

menduga-duga bahwa,

pertama di Pesantren Buntet terdapat dualisme kepemimpinan dalam penentuan kebijakan masalah pengembangan pendidikan. Tapi jika diperhatikan dari komposisi kepengurusan, ternyata ada beberapa nama kiai yang menjadi pengurus di LPI maupun YPI. Kedua, masing-masing lembaga itu memiliki peran yang sama yaitu melayani kebutuhan pendidikan masyarakat dalam bidang pendidikan, LPI mengkoordinasikan lembagalembaga pendidikan Islam yang bersifat pendidikan luar sekolah (PLS) seperti madrasah diniyah, madrasah masjid dan majlis ta'lim, Sedangkan YPI mengkoordinasikan lembaga pendidikan yang bersifat pendidikan formal seperti MI NU, MTs NU, MA NU MAK NU, AKPER. ${ }^{2}$

Menurut KH. Adib Rofi'uddin, pada tahun 1999,

${ }^{2}$ Wawancara dengan KH. Adib Rofi'uddin Izza, pada tanggal 30 Agustus 2016, di kediamannya di Buntet Pesantren. 
adanya tuntutan pemerintah bahwa setiap lembaga harus ada yayasan. Karena hal itu, akhirnya KH. Abdullah Abbas sebagai sesepuh memanggil seluruh kiai, para guru dan para asatidz di Buntet Pesantren untuk melakukan rapat. Kemudian di situ ia langsung menyampaikan kepada para kyai dan para asatidz bahwa untuk lebih efisiennya, YPI dan LPI digabung. KH. Abdullah Abbas berhasil mengoptimalkan upaya meningkatkan kualitas dan kuantitas pendidikan dengan memadukan antara Sistem Salaf dan Sistem Kholaf dengan membentuk sebuah Yayasan Lembaga Pendidikan Islam (YLPI).

Dengan dibukanya lembaga pendidikan yang bersifat keagamaan, keumuman dan kejuruan, maka Pesantren Buntet dapat dikategorikan sebagai Pondok Pesantren Terpadu yang mampu memadukan ketiga materi sekaligus yaitu keagamaan-keumumankejuruan. Karena itu, para Kiai Buntet telah mempertimbangkan keinginan masyarakat agar lembaga- lembaga pendidikan yang ada di lingkungan Pesantren Buntet tidak hanya berorientasi pada keagamaan, tetapi sekaligus juga keumuman dan kejuruan/ keterampilan.

Ditambah dengan perkembangan YLPI yang sangat baik. Semua pengurus berfungsi dan semua kyai mendukung. Semakin kokoh kesatuan dan persatuan, bidang pendidikan semakin baik, masalah pembangunan fisik seperti gedung sekolah di perbanyak, sarana-prasarana seperti laboratorium komputer dan Lembaga Bahasa Asing semakin baik.

Para kiai pada dasarnya mengelola Pondok Pesantren Buntet dengan penuh kesungguhan. Mereka berjuang melakukan berbagai revisi dan inovasi atau perubahan. Revisi yang dilakukan para kiai Buntet adalah berusaha menjadikan "lembaga sosial keagamaan" menjadi sebuah sistem lembaga kependidikan. Sedangkan inovasinya, melakukan berbagai perubahan dan mengimplementasikan visi yang telah diupayakannya itu dalam bentuk mendirikan beberapa lembaga pendidikan baik dalam bentuk madrasah, 
sekolah umum ataupun sekolah kejuruan.

\section{Pengaruh KH. Abdullah Abbas Sebagai Kiai Khos di Indonesia}

Untuk mengetahui kapan dan bagaimana istilah kiai khos muncul di kalangan NU, penulis mendapat sumber data yang menjelaskan bahwa istilah kiai khos di NU muncul tidak lepas dari peran $\mathrm{KH}$ Abdurrahman Wahid.

Dilihat dari sosoknya, sebenarnya figur para kiai khos oleh Gus Dur adalah para kiai sepuh yang tidak mengerti politik. Mereka adalah para kiai pengasuh pesantren yang hanya mengerti kitab kuning dan tidak pernah bersentuhan dengan politik praktis. Mereka memang memiliki kapasitas ilmu agama dan moralitas yang tinggi. Mereka adalah para kiai yang hidup sederhana, dekat dengan rakyat dan menjadi teladan dalam kehidupan masyarakatnya. Karena hanya mengurus rakyat dan pesantren, para kiai itu memang mengerti betul berbagai problem kehidupan rakyat bawah. Meski dekat dengan rakyat namun mereka tidak terkenal di kalangan elit poltik, karena media massa kurang melakukan ekspos terhadap kehidupan mereka.

Insting politik Gus Dur yang peka menangkap fenomena ini, kemudian dengan kepiawaiannya memainkan simbol sosial ini dalam ranah poltik. Setiap event politik yang penting dan monumental, Gus Dur selalu menyebut peran kiai khos. Akibatnya, semua orang membayangkan betapa besar dan pentingnya peran kiai khos dalam dunia politik Indonesia saat itu. Lebih-lebih media massa mencover berbagai berita tentang berbagai kelebihan yang dimiliki oleh para kiai khos.

Sejak saat itu, istilah kiai khos menjadi simbol politik yang bisa mendongkrak status sosial para kiai yang ada di dalamnya. Berbagai tokoh politik berebut datang untuk meminta restu dan dukungannya. para pejabat tinggi bergiliran ke pesantren asuhan para kiai khos untuk memperkuat posisi dan kedudukannya. Tidak hanya para pejabat dan tokoh politik, para pengusaha juga datang mendekat ke kiai khos. Hampir setiap hari kiai khos menerima tamu dari Jakarta, baik pejabat, tokoh politik maupun pengusaha. Dan pesantren kebanjiran bantuan dari berbagai pihak, karena masing-masing berlomba membantu berbagai program pesantren yang dimiliki oleh kiai khos. Pendeknya, status sosial kiai khos naik drastis, dan ini berimbas pada kiai-kiai yang lain dan dunia pesantren pada umumnya. Dampak lebih lanjut dari 
naiknya status sosial ini adalah meningkatnya nilai ekonomi bagi komunitas kiai khos maupun orangorang yang ada di sekitarnya.

Langkah politik Gus Dur makin mantap ketika jajaran kiai khos bertambah dengan masuknya sejumlah tokoh sepuh, tiga Abdullah: KH. Abdullah Salam, KH. Abdullah Faqih, dan KH. Abdullah Abbas. Yaitu pada saat Gus Dur bersilaturrahmi ke Buntet Pesantren, Pesantren Langitan, dan Pesantren Pati untuk menemui mereka, fenomena kiai khos semakin meluas. Momentum paling tepat untuk melukiskan peran kiai khos ini adalah pada awal reformasi. Dengan mengatas-namakan

keputusan mereka, Gus Dur, disertai satu langkah jitu, meraup dukungan warga NU.

Pada kenyataannya, beberapa kiai berhasil dimunculkan oleh Gus Dur menjadi kiai khos, di situ tampak kearifan para kiai dan sekaligus kepiawaian Gus Dur. Antara Gus Dur dengan para kiai khos terjalin 'simbiosis mutualisme', saling menguntungkan. Meskipun berangkat dari niat ikhlas sematamata, namun bagi para kiai sepuh pemberian gelar tersebut berdampak cukup besar terhadap posisi sosial, politik, dan bahkan ekonomi mereka. Antara Gus Dur dan kiai khos saling membantu pribadi masing-masing untuk muncul sebagai tokoh nasional yang disegani. Gus Dur dalam lapangan politik, para kiai sepuh pada lahan spiritual.

Menurut penuturan dari $\mathrm{KH}$. Adib Rofi'uddin, kiai khos bermakna kyai sepuh yang sudah tidak mengurusi urusan duniawi melainkan hanya mengurusi urusan ukhrowi dan kemaslahatan ummat. Pernyataan ini dapat memperjelas bahwa KH. Abdullah Abbas disebutsebut sebagai kiai khos adalah karena kesepuhannya, kharismatik, terpandang, dan memiliki daya pikat dan pengaruh yang luar biasa. KH. Abdullah Abbas-pun seorang kiai yang memangku pesantren yang setiap hari mempelajari ajaran agama islam dan memimpin jalannya pesantren. Ia juga yang memiliki banyak santri, orang tua santri, dan para tetangga santri, serta komunitas santri dan alumni santri yang kemudian pantaslah jika indikator tersebut membuat julukan kiai khos pantas disandangkan oleh $\mathrm{KH}$. Abdullah Abbas.

Maka tepat kiranya Hiroko Horikoshi mengatakan dalam bukunya bahwa, Peran kiai yang tidak semata-mata dalam masalah keagamaan tetapi juga masalahmasalah sosial secara luas, semakin memperkuat pengaruhnya dalam dunia politik. Kiai telah memperoleh kepercayaan besar dari masyarakat 
luas untuk mengurusi berbagai masalah, termasuk di dalamnya urusan politik. Kiai yang begitu tinggi itu tak tergoyahkan dihadapan para pejabat pemerintah. Dan keadaan ini dimanfaatkan sebaikbaiknya oleh kiai untuk kepentingan masyarakat.

Dinobatkannya KH. Abdullah Abbas sebagai Kiai Khos pada masa KH. Abdurrahman Wahid, telah membuat Kiai Dullah menjadi rujukan berbagai kalangan. Seperti halnya pada tahun 1999 masa reformasi Indonesia, pemilihan umum calon Presiden dan wakil Presiden telah dimulai. Setiap partai politik mulai ancang-ancang mempersiapkan siapa kandidat calon Presiden yang pantas melenggang maju untuk dicalonkan. Begitupun pula kaum nahdliyyin yang notabene memilih Partai Kebangkitan Bangsa (PKB).

Peran kiai dalam rekrutmen capres-cawapres mulai mengemuka sejak keluarnya keputusan politik Buntet. Bersamaan dengan 30 kiaikiai khos dari Pulau Jawa maupun luar Jawa, yang sebelumnya mereka telah melakukan shalat istikhoroh untuk meminta petunjuk kepada Allah siapa yang pantas untuk menjadi Presiden, kemudian dikumpulkan untuk melakukan musyawarah masyayikh di Buntet Pesantren, tepatnya di kediaman KH.
Abdullah Abbas. Menurut penuturan KH. Anas Arsyad. Pertemuan ini diinisiasi oleh Rabithah Ma'ahid Islamiyah.

Dalam bukunya, Munawar Fuad Noeh menuliskan, bersamaan dengan 30 kiai-kiai khos, $\mathrm{KH}$. Abdullah Faqih, Langitan mengadakan pertemuan di Buntet Pesantren (Cirebon), yang diasuh oleh Abdullah Abbas. pada tanggal 9 Maret 1999, pertemuan ini dikenal luas dengan istilah Pertemuan Buntet I (satu).

Alasan mengapa musyawarah masyayikh ini dilakukan secara terbuka di Buntet Pesantren, karena ketokohan KH. Abdullah Abbas dan posisinya dalam kedekatan hubungan antara KH. Abdullah Abbas dengan KH. Abdullah Faqih dan KH. Abdurrahman Wahid. Oleh karena itu pertemuan Buntet I sangat jelas disebutkan bahwa para kiai secara terbuka memberikan keputusan dan izin untuk Gus Dur maju sebagai Calon Presiden.

Para kiai ahirnya melanjutkan pertemuan lagi di Hotel Grand Hyatt Jakarta, di kediaman Fuad Bawazir, kemudian untuk lebih memantapkan hasil musyawarah, diadakan lagi pertemuan di Hotel Acacia, Jakarta dan hasil keputusan terahir di umumkan di PBNU. Yaitu KH. Abdurrahman Wahid menjadi satusatunya calon presiden yang diusung 
oleh Partai Kebangkitan Bangsa (PKB) pada pemilihan presiden tahun 1999. Serangkaian pertemuan ini dikenal dengan nama pertemuan Buntet I.

Pada pemilihan presiden tahun 2004, diadakan lagi Pertemuan Buntet II, Dinamakan Buntet II karena karena pertemuan tersebut dihadiri oleh Kiai-Kiai senior yang sebelumnya terlibat dalam pertemuan Buntet I (termasuk KH. Abdullah Abbas). Seperti halnya yang dikutip dari Buku Titik Tengkar Pesantren, bahwa dalam kasus pencalonan kembali Gus Dus sebagai Presiden RI untuk periode pemilu 2004, menurutnya tidak lepas dari tausiyah ulama. Lewat beberapa kali pertemuan Kiai khos seperti di Pesantren Buntet Cirebon, Mataram, NTB dan Langitan, Tuban.

Selain itu agenda politik yang dibahas juga terkait erat dengan keputusan Buntet I. pertemuan Buntet II sendiri berlangsung tanggal 24 April 2004 di pesantren Qomarul Huda, Pagu, Lombok Tengah, Nusa Tenggara Barat. Sama halnya dengan Buntet I, pertemuan Buntet II juga menetapkan Gus Dur sebagai satusatunya capres RI yang didukung mereka pada pemilihan presiden 2004. Menariknya, dalam Buntet II juga memutuskan agar Kiai-Kiai yang terlibat dalam pertemuan memiliki hak representatif dalam
Tim Sembilan PKB yang memiliki kewenangan merumuskan namanama capres dan cawapres yang akan diajukan dalam pemilihan presiden 2004.

Pertemuan Buntet I dan II terhadap pencalonan Gus Dur, mulai bergeser setelah keluarnya keputusan Mahkamah Agung (MA). Akhirnya KPU mengeluarkan dua surat keputusan (SK) Nomor 31 Tahun 2004. Terkait dengan pencalonan Gus Dur. Hal ini berdampak pada gagalnya Gus Dur menjadi calon Presiden pada Pilpres 2004. Itulah perbedaan yang signifikan antara Pertemuan Buntet I dengan Pertemuan Buntet II.

\section{Penutup}

Pada masa kepemimpinan $\mathrm{KH}$. Abdullah Abbas, Buntet Pesantren semakin berkembang. Antara lain berhasil mengoptimalkan upaya meningkatkan kualitas dan kuantitas pendidikan dengan memadukan antara sistem salaf dan sistem kholaf dengan membentuk sebuah Yayasan Lembaga Pendidikan Islam (YLPI). KH. Abdullah Abbas juga mendirikan Perguruan Tinggi yaitu Akademi Perawatan yang pada saat itu AKPER Buntet Pesantren merupakan sekolah keperawatan pertama di lingkungan pondok pesantren se-wilayah Jawa Barat. 
Sebagai kiai khos, KH. Abdullah Abbas mempunyai pengaruh besar dalam kehidupan sosial keagamaan dan politik di Indonesia. KH. Abdullah Abbas menjadi rujukan banyak kalangan. Banyak yang datang ke Buntet Pesantren untuk menemui KH. Abdullah Abbas, ada yang bermaksud untuk sekedar berguru, nyantri, sowan, silaturrahmi, meminta doa, sampai pejabat daerah kelas kuwu, bupati, bahkan presiden, yang datang dengan maksud politis dan ingin meraup suara masyarakat agar dikenal dekat dengan pesantren dan kiai karena ia telah mendatangi kiai khos dan memuluskan niat mereka. Kiai khos telah dikenal banyak orang karena kemasyhuran dan kharismanya.

\section{Daftar Pustaka}

\section{Buku}

AG, Muhaimin. 2001. Islam dalam bingkai Budaya Lokal potret dati Cirebon. Jakarta: Logos.

Agama, Departemen. 2004. Pola Pengembangan Pondok Pesantren: Petunjuk Teknis Pondok Pesantren. Jakarta: Direktorat Jenderal Kelembagaan Agama Islam.
Ali, Surya Dharma. 2013. Paradigma Pesantren: Memperluas Horizon Kajian dan Aksi. Malang: Maliki Press.

Amidjaja, Rosad dkk. 1985. "Pola Kehidupan Santri Pesantren Buntet Desa Mertapada Kulon Kecamatan Astanajapura Kabupaten Cirebon. Yogyakarta: P3KN.

Azra, Azyumardi. 2012. Pendidikan Islam: Tradisi dan Modernisasi di Tengah Tantangan Millenium III. Jakarta: Prenada Media Group.

Bruinessen, Martin Van. 1995. Kitab Kuning, Pesantren dan Tarekat. Bandung: Mizan.

Dzofier, Zamakhsyari. 2011 Tradisi Pesantren (Studi Pandangan Hidup Kiai dan Visinya Mengenai Masa Depan Indonesia). Jakarta: LP3ES.

El Saha, Ishom dan Mastuki Hs (Editor). 2003. Intelektualisme Pesantren. Jakarta: Diva Pustaka.

Hadi, Munib Rowandi Amsal. 2012. Kisah-kisah dari Buntet Pesantren Cirebon. Cirebon : Kalam "komunikatif dan islami".

Hasan, Ahmad Zaeni. 2000. "Perlawanan dari Tanah Pengasingan, Kiai Abbas, 
Pesantren Buntet dan Bela Negara. Jakarta: Elsas.

Horikoshi, Hiroko. 1987. Kiai dan Perubahan Sosial. Jakarta: P3M.
Kuntowijoyo, 1994. Metodologi Sejarah, Yogyakarta: Tiara Wacana Yogya. 